\title{
La politique du conseil général de l'Indre en faveur du réseau ferré local (1852-1909)
}

Marc du Pouget

\section{OpenEdition}

\section{Journals}

Édition électronique

URL : https://journals.openedition.org/rhcf/2044

DOI : 10.4000/rhcf.2044

\section{Éditeur}

Rails \& histoire

\section{Édition imprimée}

Date de publication : 2 mai 2002

Pagination : 176-180

ISBN : 00996-9403

ISSN : 0996-9403

\section{Référence électronique}

Marc du Pouget, « La politique du conseil général de l'Indre en faveur du réseau ferré local

(1852-1909) ", Revue d'histoire des chemins de fer [En ligne], 24-25 | 2002, mis en ligne le 13 avril 2015, consulté le 22 avril 2022. URL : http://journals.openedition.org/rhcf/2044 ; DOI : https://doi.org/

$10.4000 /$ rhcf.2044 
Troisième partie

Vie et mort des chemins de fer secondaires :

destins comparés 


\section{La politique du conseil général de l'Indre en faveur du réseau ferré local (1852-1909)}

\section{Les premiers projets de l'Empire}

Après la construction de la ligne Paris-Toulouse, achevée en 1847 à Châteauroux et en 1856 à Limoges, de nombreuses réclamations s'élevèrent pour réclamer de nouvelles voies ferrées dans l'Indre.

Un débat s'instaura entre les notables, l'État et les compagnies concessionnaires.

Les plus ardents défenseurs du rail berrichon étaient les députés de l'Indre, le comte de Bryas, et le maire de La Châtre et président du conseil général Delavau. Un cercle influent se constitua en 1853 à Paris dans les locaux de l'imprimerie du Castelroussin Napoléon Chaix : la Société du département de l'Indre à Paris. Son premier bulletin consacra un chapitre à la question ferroviaire et à l'établissement de chemins de fer transversaux.

Une compagnie David, Souvigny et Cie construisant la ligne La Rochelle-Poitiers tentait d'obtenir une concession Rochefort-Strasbourg avec passage par Chauvigny, Saint-Savin et la vallée de la Creuse. Le conseil général de l'Indre approuva son projet dans sa session de 1852.

Un autre tracé unissant Port-de-Piles à Montluçon par Mézièresen-Brenne et la vallée de la Claise était défendu par Henri Navelet, maire et conseiller général de Mézières : faute d'appui financier, il ne vit pas le jour.

Un troisième projet était soutenu par Muret de Bort, industriel, ancien député, président de la société d'agriculture : Tours-Montluçon par la vallée de l'Indre et Châteauroux. Le principal avantage invoqué était, en rejoignant le bassin de Commentry, d'obtenir une houille bon marché pour moderniser les forges et alimenter les machines à vapeur. En 1855, une Compagnie du Sud-Ouest demande au gouvernement la concession de quatre lignes nouvelles, dont Tours-Clermont par Châteauroux. En 1858, l'annonce était faite par le préfet de l'Indre de la mise à l'étude du projet. 
Mais la politique gouvernementale suivait des « valses-hésitation » dont l'Empereur était coutumier, avec l'avantage donné aux compagnies sur les notables, par les conventions de juillet 1858, ou au contraire avec la lettre impériale du 5 janvier 1860 relançant les grands travaux.

En 1861, un vœu départemental réclame une ligne Montmorillon-Châteauroux par Le Blanc et la Brenne : vœu pieux. On se dirigea alors vers des projets de " chemins de fer vicinaux ", réalisés à l'instar des chemins de grande communication par le service vicinal. En 1864 fut voté un projet Châteauroux-La Châtre, maillon du Tours-Montluçon qui tardait à venir.

La loi du 12 juillet 1865 sur les chemins de fer d'intérêt local modifia ce projet en prévoyant des subventions d'État de 25 à $30 \%$ pour la création de petites lignes. L'assemblée départementale approuva en août 1865 divers projets : Luant (sur la ligne de Limoges)-Le Blanc, Tours-Montluçon, Tours-Vierzon par Valençay, Le Blanc-Argenton. Une session extraordinaire de décembre 1866 approuva la concession à une société belge d'un Tours-Montluçon : mais le refus du conseil général d'Indre-et-Loire fit échouer le projet. Nouvelle donne de l'État avec la loi du 17 juillet 1868 qui déclarait d'utilité publique le Tours-Montluçon.

D'autres projets virent le jour: en 1869, une ligne Port-Boulet-La Châtre par Chinon, Richelieu, Châtellerault, Le Blanc et Argenton reçoit un crédit d'études de 10000 F. En 1870 est envisagée une ligne Gièvres-Chabris-Le Blanc avec possibilité de passage à Levroux.

\section{La Troisième République}

Après la défaite de 1870, les projets reprirent. Un Tournon-La Châtre fut adopté par le conseil général en 1871, concédé à la Compagnie Séguineau et Jackson, puis Compagnie de Bressuire à Poitiers. Celle-ci, faute de travaux, dut abandonner après trois ans de contentieux.

Le plan Freycinet, soutenu par les républicains hostiles aux compagnies, allait, à partir de 1878, relancer l'action de l’État. La ligne Tours-Montluçon fut rachetée à la Compagnie d'Orléans, chargée néanmoins de construire et de livrer la ligne. Le tronçon de Loches à Châteauroux fut mis en service en 1880, celui de Châteauroux à La Châtre en 1882, celui de La Châtre à Montluçon en 1884.

La convention du 20 novembre 1883 attribuait à la Compagnie d'Orléans les lignes d'intérêt général dans l'Indre. La participation des départements était nécessaire pour l'achat des terrains et la construction des voies : chaque année, les ingénieurs des Ponts et Chaussées rendent compte à l'assemblée départementale de l'état des travaux. 
A partir de 1884, de nouveaux tronçons furent mis en service : Urciers-Lavaufranche en 1886, Le Blanc-Port-de-Piles et Le Blanc-La Trémouille en 1888, Le Blanc-Argenton et Le Blanc-Poitiers en 1889, Issoudun-Saint-Florent en 1893.

Le projet Le Blanc-Argent connut des difficultés : abandonné en 1886, il fut repris à partir de 1890, le conseil général de l'Indre ayant accepté une construction à voie étroite. Mais la Compagnie d'Orléans proposa de modifier le tracé initial en évitant Chabris au profit de Selles-sur-Cher. En 1896, le conseil général interjeta appel au Conseil d'État, invoquant une déclaration d'utilité publique de 1882 pour le tracé initial. Il obtint gain de cause par arrêt du 28 juillet 1898. Les travaux furent réalisés de 1899 à 1902. En 1903, le département empruntait près de $500000 \mathrm{~F}$ pour payer sa part de subvention. L'ouverture des lignes Argenton-La Châtre (1903) et Guéret-La Châtre (1906) marqua la fin des créations de voies ferrées dans l'Indre.

\section{Les tramways}

Pensant, grâce au plan Freycinet, être déchargé de ses obligations pour les lignes d'intérêt général, le conseil général de l'Indre envisagea la création d'un réseau de tramways plus économique et plus proche du réseau routier. En 1883, il signa avec la Compagnie des chemins de fer départementaux, concessionnaire en Indre-et-Loire, une convention de construction et d'exploitation de six lignes; le Conseil des Ponts et Chaussées repoussa le projet comme irréaliste et il fallut se contenter d'un seul projet, Châteauroux-Levroux-Vatan, qui échoua, faute d'accord de la majorité, puis de la compagnie.

Les projets reprirent après l'achèvement de l'essentiel des lignes d'intérêt général. En 1897, le département prévoyait l'établissement de trois lignes : Châteauroux-Levroux-Valençay, Issoudun-Vatan-Graçay, Le Blanc-Argenton avec embranchement vers Chaillac, soit au total $162 \mathrm{~km}$.

La Compagnie générale de construction Saint-Denis chargée de la construction créa une filiale, la Compagnie des tramways de l'Indre, reconnue par l'État en 1901. L'ouverture des lignes fut réalisée entre 1902 et 1907.

Dès avril 1903, une nouvelle délibération était prise pour la création d'un réseau complémentaire : cinq lignes nouvelles prévues en 1904, onze en 1907, réduites à cinq.

Un traité de concession fut finalement signé en 1909 pour six lignes d'un parcours de $180 \mathrm{~km}$, mais les discussions ne purent aboutir 
avec l'État ni avec la Compagnie des tramways de l'Indre. La guerre mit tout le monde d'accord...

La longue histoire des chemins de fer dans l'Indre donne une impression d'incohérence : modifications de législation, jonctions de lignes dans des lieux isolés par économie, absence de volonté politique ou volonté exagérée de desserte égale des cantons aux dépens des relations de Châteauroux (dont la liaison avec Le Blanc et Poitiers, Guéret, Bourges ou Blois reste difficile), mauvais entretien du matériel.

Pourtant ces chemins de fer locaux si désirés, si critiqués, bénéficièrent d'un capital de tendresse, comme le « tacot» d'Issoudun ou le «tortillard» du Blanc-Argent. Les hommes et les machines complaisamment photographiés sur les cartes postales du début du siècle témoignaient d'un progrès technique adapté au terroir dont nous avons encore la nostalgie.

\section{Sources et bibliographie}

- D. Bruneau, Les Voies de communication dans l'Indre, 1870-1914, 2 vol. dact., vers 1960, Arch. dép. Indre F 798/13 et 14.

- M. Wolkowitsch, «Le redéploiement des activités ferroviaires dans le département de l'Indre », Revue d'histoire des chemins de fer $n^{\circ} 9$ (automne 1993), p. 144-162. - Arch. dép. Indre, série S. 
Revue d'histoire des chemins de fer 24-25 (printemps - automne 2001)

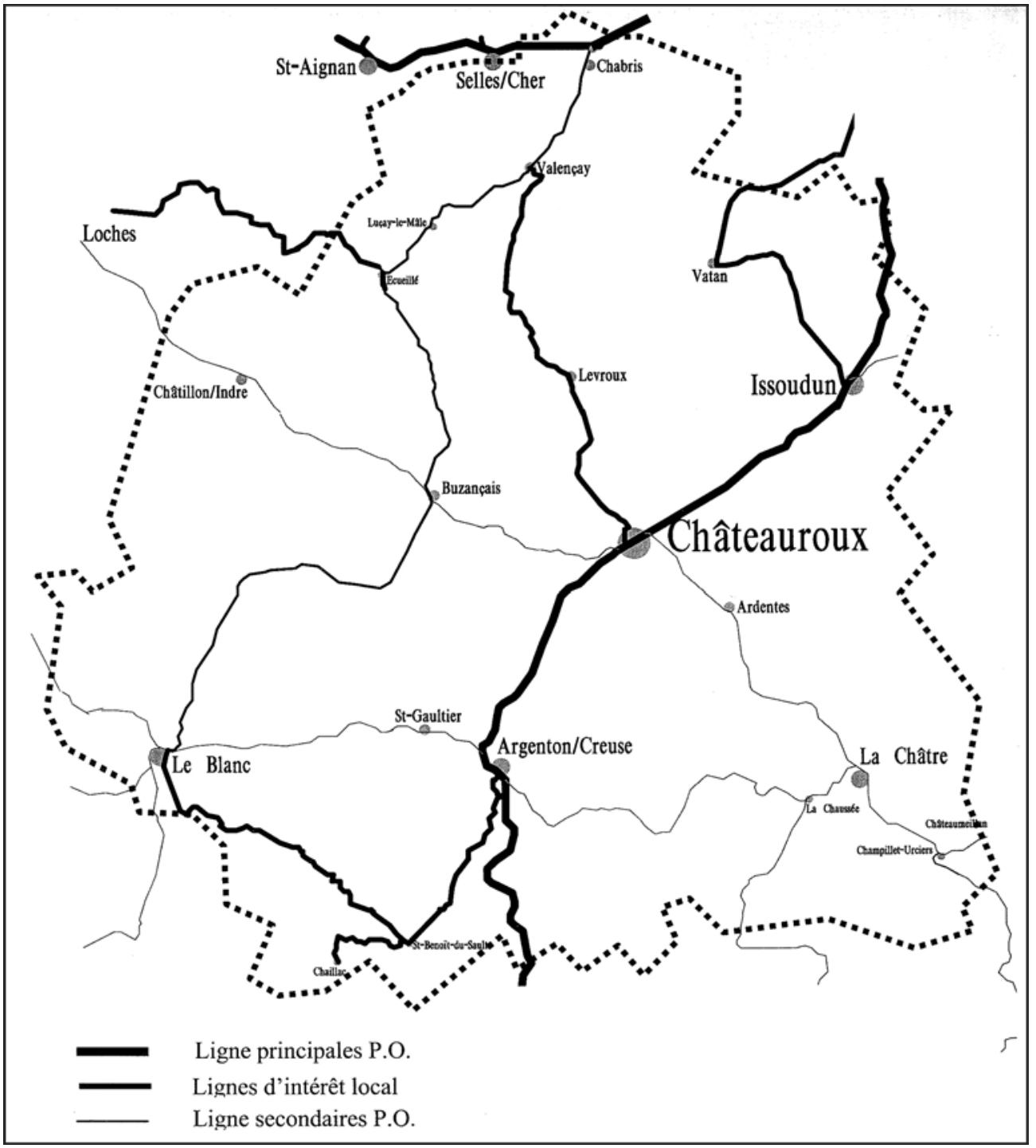

Figure 1 : Les chemins de fer dans l'Indre.

๑ É. Auphan 